\title{
The safety and efficacy of different methods used for the closure of the appendiceal stump in laparoscopic appendectomy
}

\author{
Hüseyin Kerem Tolan, Gürhan Baş, Fikret Ezberci, Tolga Canbak, Adnan Özpek, \\ Abdullah Şişik, Metin Yücel, İlyas Kudaş, İbrahim Atak \\ Department of General Surgery, Health Sciences University Ümraniye Training and Research Hospital, İstanbul, Turkey
}

\begin{abstract}
Introduction: The aim of the present study was to compare different techniques for the closure of an appendiceal stump (CAS) with respect to safety.

Materials and Methods: A retrospective review of the records of 232 patients who underwent a successful laparoscopic operation for acute appendicitis was conducted.

Results: In the 232 laparoscopic appendectomies (LA) performed in the clinic, the median age of the patient was 31 years (range: $16-72$ years). The female/male ratio was $42.6 \% / 57.4 \%$. Of all the cases, CAS was performed with an Endoloop (Ethicon, Inc., Somerville, NJ, USA) in 183, Hem-o-lok clips (Teleflex, Inc., Wayne, PA, USA) were used in 32, and both items were used in 14 cases, according to the intra-operative decision of the surgeon. In 3 cases the CAS was achieved using a laparoscopic stapler due to inflammation in the stump of the appendix.

Conclusion: CAS in LA can be performed safely using an Endoloop, Hem-o-lok clips, or a stapler in patients with a mild to moderately inflamed appendix base. In cases of enlarged and severely inflamed, or wide appendix stump, a stapler is a safe option to prevent any stump leakage.

Keywords: Closure of the apendiceal stump (CAS); endo-loop; endo-stapler; hem-o-lok; laparoscopic appendectomy.
\end{abstract}

\section{Introduction}

Since the first appendectomy was performed and presented in 1889 by Charles Mc Burney, the acute appendicitis has been one of the most common surgeries performed by the general surgeons. ${ }^{[1]}$ In time different surgical skin incisions for appendectomy and various techniques for the appendectomy had been developed. First described appendectomy has been widely and safely used in time with different incisions and techniques with the main concern being the safe closure of the appendix stump (CAS).

After the integration of laparoscopy in general surgical practice surgeons became interested in doing a laparoscopic appendectomy. It was a Gynecologist named Kurt Semm who first described and performed the laparoscopic appendectomy (LA) in 1982. In his original description the technique was described as eligible for an intra-corporeal, 
extra-corporeal, loop ligation etc. for the CAS. ${ }^{[2]}$ Although this technique was used in the beginning with the development of new instruments for the laparoscopy in time other options for the division of the mesoappendix and closure of the appendix stump has been used in time. ${ }^{[3]}$

Starting from a simple extra-corporal ligation, endo-loops, titanium clips, laparoscopic endo-staplers has been used and compared to each other for safety in CAS in time. ${ }^{[4-7]}$ All of these techniques had some benefits but also some major draw backs when compared.

The aim of this retrospective clinical study was to compare the safety and efficacy of the use of endo-loop ligation, hem-o-lok clip application, both endo-loop and hem-olok clip application and Endo-stapler use for the CAS in laparoscopic appendectomy surgeries.

\section{Materials and Methods}

In this sudy we retrospectively examined the 232 patients that were successfully laparoscopically operated with the diagnosis of acute appendicitis between the years 20102014 in our clinic.

The laparoscopic approach was standardized with the use of a 11-mm infra-umbilical port, 5-mm supra pubic port, and 10-mm left lower quadrant port. A 30-degree 10-mm laparoscope was inserted. Than the patients position was changed into a head down and right side up position. The mobilization \& the resection of the mesoappendix was done by the LigaSure ${ }^{\circledR}$ (ValleyLab, Inc., Boulder, Colorado). The appendix itself was also resected by the Ligasure after the ligation of the appendix stump. According to the size of the stump of the appendix and the surgeon's intraoperative decision; 2/0 Vicryl Endoloop ${ }^{\circledR}$ Ligatures (Ethicon Endo-Surgery, Somerville, NJ, USA), large or extra-large sized Hem-o-lok clip (Weck Closure Systems, Research Triangle Park, NC) or both of these were used to close the appendix stump. In some cases with severe inflammation at the radix of the appendix we used an endostapler (Covidien Endo GIA ${ }^{\mathrm{TM}}$ Blue $3.5 \mathrm{~mm}$ ) for the CAS. After the resection the appendix was removed through the 11-mm umbilical port with an endo-bag when needed due to the size of the specimen. Drains were not routinely used.

The cases were grouped into four according to the choice of the surgeons' CAS technique. The groups were; endo-loop vicryl used as the CAS group, Hem-o-lok group, endo-loop and Hem-o-lok used group and the stapler used group. These 4 groups were compared among themselves for the stump leak.

\section{Results}

In five years of time 232 laparoscopic appendectomies were performed in our clinic. The median age of the cases were 31 (16-72). Female/male ratio was 99/133. 183 of all the cases the CAS was done by the endo-loop, 32 of the cases hem-o-lok clips were used and 14 of the cases both the endo-loop and hem-o-lok's were used according to the intra-operative decision of the operating surgeon. In 3 of the cases the CAS was done by the endo-stapler. This was due to the inflamed appendix stump which was tought not to be able to be safely closed by the use of the endo-loops or the hem-o-lok clips alone by the operating surgeon.

The endo-loop and the hem-o-lok clip was both used at the same time in 14 of the cases where the surgeon performing the operation was not satisfied by the use of only one of the techniques alone for the CAS.

Severe inflammation of the stump that will not permit the use of the endo-loop or the Hem-o-lok clip due to the fragility of the Cecum, so for the CAS laparoscopic endo-stapler was used.

No matter which technique for the CAS was used there were no leaks from the stumps closed after the laparoscopic appendectomies.

\section{Discussion}

Acute appendicitis has been one of the most common surgical emergencies in surgical practice. The curative treatment of an acute appendicitis is the appendectomy which can be done by an open approach or laparoscopically. The decision of the technique depends on the performing surgeons preference and the expertise after the concents taken from the patients. ${ }^{[8]}$

The laparoscopic technique has the benefits of; diagnostic accuracy, ability to make an abdominal exploration, lower risks of postoperative complications and adhesions, less post-operative pain, shorter hospitalisation periods, better cosmetic results, less wound infection rates and early return to work and daily life. But still no superiority to the open classic technique was demonstrated in the literatures comparing LA and classic appendectomy. ${ }^{[9-13]}$

Besides these benefits in laparoscopy there are some dis- 
advantages and limitations of it such as; the long operation times for performing a laparoscopic surgery, complications of the laparoscopic techniques and the higher costs of the laparoscopic surgery due to the devices used. ${ }^{[14,15]}$ For these reasons the laparoscopic technique is not accepted as the gold-standard approach in acute appendicitis. But due to the advantages of minimally invasive techniques it has been widely used . Also the diagnostic use and at the same time therapheutic use of the laparoscopy is an advantage of the LA in a suspicion of an acute appendicitis patient. ${ }^{[16]}$

The most important step in the appendectomy, either in open technique or the laparoscopic technique, is the CAS. In the classic technique the suture ligation is mostly used, but in the laparoscopic approach the CAS varies according to the surgeons experience and preference. There is no common decision made on CAS in laparoscopy in the literature which may change from surgeon to a surgeon. Even tough different CAS techniques were used in ur clinic there were no leaks in any of our cases.

Various CAS closure techniques has been described in the literature such as; endo-loops, metal titanium clips, polymer clips and endostaplers etc. But every technique has its own benefits and handicaps. ${ }^{[5,17-21]}$ For example use of endo-loop for CAS in some cases may prolong the surgery time due to the need for an experience for the application and alignment of the loop. ${ }^{[22]}$ The titanium clips that may be used also has a risk of displacement during the manipulations in the laparoscopy. ${ }^{[23]}$ The non-absorbable polymer hem-o-lok clips; that were popularised, widely and safely used by the urologists in the nefrectomies, has also been used in the LA surgeries. ${ }^{[7,18,22,24]}$ There are no Hem-olok clip failures in the literature, when the Federal Drug Administration's (FDA) databases are searched. ${ }^{[25]}$ Also the recent studies cunducted that compared; the metal clips, hem-o-lok clips and endoloop ligatures demonstrated similar surgically related complication rates suggesting all of them as safe, feasible and cost-effective techniques for the CAS. ${ }^{[26,27]}$

Inflamed appendix may be thick in size and the cecum may be fragile at the stump thus diameters above $10 \mathrm{~mm}$ may not be apropriate to use a metal or polymer clips for CAS. ${ }^{[28]}$ The staples were described to be the best technique for the CAS but they are also the most expensive technique. ${ }^{[6,29]}$

Even tough there is no gold standart CAS technique has been described, all these techniques may be used for a safe CAS. Technique that will be preffered for the CAS depends on the appereance of the appendix in the operation like a necrosis at the radix of the appendix, the devices that are available in the operation room and the performing surgeons decision and experience.

To describe and define a gold standart for a CAS in laparoscopy, prospective randomised studies should be conducted with larger sub-groups of patients for each CAS techniques described in the literature.

\section{Conclusion}

LA is a widely used, safe and an effective surgical technique used in the diagnosis and also the treatment of acute appendicitis. Our results allows us to conclude that the stump closure during a LA can be performed safely by; endo-loops, endo-staplers or hem-o-lok clips in patients with a mild to moderately inflamed appendix base. Endo-staplers are safe devices that can be used for CAS but they are expensive. In the cases of enlarged and severely enflamed, wide appendix stumps; endo-stapler can be a safe option to prevent any stump leak.

\section{Disclosures}

Ethichs Committee Approval: The study was approved by the Local Ethics Committee.

Peer-review: Externally peer-reviewed.

Conflict of Interest: None declared.

\section{References}

1. Rutkow IM. Appendicitis: the quintessential American surgical disease. Arch Surg 1998;133:1024. [CrossRef]

2. Semm K. Endoscopic appendectomy. Endoscopy 1983;15:59-64. [CrossRef]

3. Galatioto C, Guadagni S, Zocco G, Mazzilo M, Bagnato C, Lippolis $\mathrm{PV}$, et al. Mesoappendix and appendix stump treatment in laparoscopic appendectomy: a retrospective study in 1084 patients. Ann Ital Chir 2013;84:269-74.

4. Beldi G, Vorburger SA, Bruegger LE, Kocher T, Inderbitzin D, Candinas D. Analysis of stapling versus endoloops in appendiceal stump closure. Br J Surg 2006;93:1390-3. [CrossRef]

5. Arcovedo R, Barrera $H$, Reyes HS. Securing the appendiceal stump with the Gea extracorporeal sliding knot during laparoscopic appendectomy is safe and economical. Surg Endosc 2007;21:1764-7. [CrossRef]

6. Kazemier G, in't Hof KH, Saad S, Bonjer HJ, Sauerland S. Securing the appendiceal stump in laparoscopic appendectomy: evidence for routine stapling? Surg Endosc 2006;20:1473-6. 
7. Hanssen A, Plotnikov S, Dubois R. Laparoscopic appendectomy using a polymeric clip to close the appendicular stump. JSLS 2007;11:59-62.

8. Gorter RR, Heij HA, Eker HH, Kazemier G. Laparoscopic appendectomy: State of the art. Tailored approach to the application of laparoscopic appendectomy? Best Pract Res Clin Gastroenterol 2014;28:211-24. [CrossRef]

9. Gupta R, Sample C, Bamehriz F, Birch DW. Infectious complications following laparoscopic appendectomy. Can J Surg 2006;49:397-400.

10. Bruwer F, Coetzer M, Warren BL. Laparoscopic versus open surgical exploration in premenopausal women with suspected acute appendicitis. S Afr J Surg 2003;41:82-5.

11. Towfigh S, Chen F, Mason R, Katkhouda N, Chan L, Berne T. Laparoscopic appendectomy significantly reduces length of stay for perforated appendicitis. Surg Endosc 2006;20:495-9.

12. Olmi S, Magnone S, Bertolini A, Croce E. Laparoscopic versus open appendectomy in acute appendicitis: a randomized prospective study. Surg Endosc 2005;19:1193-5. [CrossRef]

13. Varela JE, Hinojosa MW, Nguyen NT. Laparoscopy should be the approach of choice for acute appendicitis in the morbidly obese. Am J Surg 2008;196:218-22. [CrossRef]

14. Kuwabara K, Imanaka Y, Matsuda S, Fushimi K, Hashimoto $H$, Ishikawa KB, et al. Cost of open versus laparoscopic appendectomy. Clin Ter 2008;159:155-63.

15. Sporn E, Petroski GF, Mancini GJ, Astudillo JA, Miedema BW, Thaler K. Laparoscopic appendectomy-is it worth the cost? Trend analysis in the US from 2000 to 2005. J Am Coll Surg 2009;208:179-85. [CrossRef]

16. Tan-Tam C, Yorke E, Wasdell M, Barcan C, Konkin D, Blair P. The benefits of laparoscopic appendectomies in obese patients. Am J Surg 2012;203:609-12. [CrossRef]

17. Sajid MS, Rimple J, Cheek E, Baig MK. Use of endo-GIA versus endo-loop for securing the appendicular stump in laparoscopic appendicectomy: a systematic review. Surg Laparosc Endosc Percutan Tech 2009;19:11-5. [CrossRef]

18. Partecke LI, Kessler W, von Bernstorff W, Diedrich S, Heidecke CD, Patrzyk M. Laparoscopic appendectomy using a single polymeric clip to close the appendicular stump. Langenbecks Arch Surg 2010;395:1077-82. [CrossRef]

19. Gonenc M, Gemici E, Kalayci MU, Karabulut M, Turhan AN,
Alis H. Intracorporeal knotting versus metal endoclip application for the closure of the appendiceal stump during laparoscopic appendectomy in uncomplicated appendicitis. J Laparoendosc Adv Surg Tech A 2012;22:231-5. [CrossRef]

20. Alis H, Gonenc M, Deniztas C, Kapan S, Turhan AN. Metal endoclips for the closure of the appendiceal stump in laparoscopic appendectomy. Tech Coloproctol 2012;16:139-41.

21. Shaikh FM, Bajwa R, McDonnell CO. Management of appendiceal stump in laparoscopic appendectomy-clips or ligature: a systematic review and meta-analysis. J Laparoendosc Adv Surg Tech A 2015;25:21-7. [CrossRef]

22. Delibegović S, Matović E. Hem-o-lok plastic clips in securing of the base of the appendix during laparoscopic appendectomy. Surg Endosc 2009;23:2851-4. [CrossRef]

23. Meng MV. Reported failures of the polymer self-locking (Hem-o-lok) clip: review of data from the Food and Drug Administration. J Endourol 2006;20:1054-7. [CrossRef]

24. Ponsky L, Cherullo E, Moinzadeh A, Desai M, Kaouk J, Haber GP, et al. The Hem-o-lok clip is safe for laparoscopic nephrectomy: a multi-institutional review. Urology 2008;71:593-6.

25. Hue CS, Kim JS, Kim KH, Nam SH, Kim KW. The usefulness and safety of Hem-o-lok clips for the closure of appendicular stump during laparoscopic appendectomy. J Korean Surg Soc 2013;84:27-32. [CrossRef]

26. Bozkurt MA, Ünsal MG, Kapan S, Kankaya B, Kalaycı MU, Alış $\mathrm{H}$. Two different methods for appendiceal stump closure: metal clip and Hem-o-lok clip. J Laparoendosc Adv Surg Tech A 2014;24:571-3. [CrossRef]

27. Colak E, Kement M, Ozlem N, Mutlu T, Yildirim K, Gurer A, et al. A comparison of nonabsorbable polymeric clips and endoloop ligatures for the closure of the appendicular stump in laparoscopic appendectomy: a prospective, randomized study. Surg Laparosc Endosc Percutan Tech 2013;23:255-8.

28. Strzałka M, Matyja M, Rembiasz K. Results of laparoscopic appendectomies performed with the use of titanium clips for closure of the appendicular stump. Pol Przegl Chir 2014;86:418-21. [CrossRef]

29. Swank $H A$, van Rossem $C C$, van Geloven $A A$, in't Hof $K H$, Kazemier G, Meijerink WJ, et al. Endostapler or endoloops for securing the appendiceal stump in laparoscopic appendectomy: a retrospective cohort study. Surg Endosc 2014;28:576-83. [CrossRef] 